\title{
Follicular cholangitis and pancreatitis
}

INSERM

\section{Source}

INSERM. (1999). Orphanet: an online rare disease and orphan drug data base. Follicular cholangitis and pancreatitis. ORPHA:300552

Follicular cholangitis and pancreatitis is a rare pancreatobiliary disease characterized by marked duct-centered lymphoid follicular inflammation that develops in both biliary and pancreatic ductal systems, mainly affecting the hilar bile ducts and the pancreatic head. Patients present with jaundice, abdominal pain, liver dysfunction, pruritus and/or weight loss. Histology shows lymphoplasmacytic infiltration with formation of numerous, large lymphpoid follicles around the affected bile and pancreatic ducts. 